\title{
The Specificity of Dynamic Resistance of Existing Bridge Structures in Mining Areas
}

\author{
Dawid Mrozek $^{1}$ (D) $\cdot$ Magdalena Mrozek ${ }^{1}$
}

Received: 24 February 2020 / Revised: 20 July 2020 / Accepted: 24 September 2020 / Published online: 15 October 2020

(C) The Author(s) 2020

\begin{abstract}
The article presents the results of a dynamic resistance analysis of selected existing bridge structures. The numerical calculations performed with the use of THA (time history analysis) pertained to road and rail bridges of steel and concrete structures-not paraseismically designed. The purpose of the work was to determine the dynamic resistance of objects to the influence of paraseismic impacts resulting from mining operations. The specificity of performing calculations in this area of engineering issues is presented. Real mining tremor signals, registered in the vicinity of the objects were used in the numerical analyses. The correct determination of the dynamic resistance of the object can be used as a basis for performing repair/strengthening of existing objects, which in the future will be loaded with additional paraseismic influences.
\end{abstract}

Keywords Time history analysis - Paraseismic activity $\cdot$ Dynamic resistance $\cdot$ Numerical analyses $\cdot$ Existing bridge structure $\cdot$ Gabor transform

\section{Introduction}

Bridge structures are an important element of infrastructure in urban areas. Through the use of bridge structures, it becomes possible to overcome obstacles, such as rivers or valleys. Often, such constructions are located in areas, where soil accelerations of paraseismic origin occur. In such cases, these existing objects should be subject to an estimation of dynamic resistance if they are not paraseismically designed in advance. Their value should be sufficient to safely transfer additional dynamic influences of, e.g., mining origin. There are a number of buildings erected before mining operations begin, and that is why they are usually not designed with the possible paraseismic impact properly taken into account. Additionally, during use, the bridge may be damaged or its condition will deteriorate over time (e.g., due to the impact of various atmospheric

Dawid Mrozek

dawid.mrozek@polsl.pl

Magdalena Mrozek

magdalena.mrozek@polsl.pl

1 Department of the Mechanics and Bridges, Faculty of Civil Engineering, Silesian University of Technology, RB-5, Akademicka 5, 44-100 Gliwice, Poland conditions). Hence, it becomes necessary to estimate the current resistance of the real bridge object and compare it with the predicted dynamic impact resulting from human activity in the vicinity of the bridge location.

Intensive human activity in industrial areas, manifested in mining exploitation of deposits, including hard coal, is a source of static and dynamic subsoil impacts on buildings. These impacts can cause damage to objects due to a lack of adequate protection and poor technical condition of these structures. Some regions in Poland, e.g., Upper Silesia, are constantly exposed to mining tremors with peak acceleration values of up to $2 \mathrm{~m} / \mathrm{s}^{2}$. This value is not significant compared to those recorded during seismic excitations [1]; however, the number of paraseismic impacts recorded during the year is disproportionately higher than seismic. We can observe approximately 1000 paraseismic excitations per year on $40 \mathrm{~km}^{2}$ area square. The more information could be find on [2].

The problem of design and structure analysis in the field of dynamic impact is complex [3-6] and still uncertain [7]. It is worth noting that the greatest simplifications usually relate to dynamic load [8]. It is often treated as static without its time-spectral characteristics. Strict dynamic analyses, e.g., using the load history method (THA) are not common. Most often, dynamic resistance assessment is 
carried out using simplified methods with the use of values characterizing the dynamic properties of the structure, such as frequencies and forms of natural vibrations. The results of numerical analyses can be verified with the results of tests on real objects [9-12]. The premise for conducting these type of tests, resulting from the nature of the moving load and from the point of view of the randomness of the paraseismic load, may be insufficient. In such a situation, a realistic assessment of the dynamic characteristics of the existing object [13-15] should be completed using numerical models.

In terms of construction, bridges are diverse. Thus, it becomes necessary to conduct a detailed analysis of dynamic response to the impact of mining tremors using the response history method with the use of kinematic excitations. These excitations should be a record of the course of soil acceleration change per unit of time in three orthogonal directions. It is important, in this case, that the accelerometer location is in the area of the foundation of the bridge object which is undergoing analysis. This assumption is related to the characteristics of tremors, which depend, among others, on the mining activities being carried out and the parameters of the soil lying in the area, where the bridge is located.

The subject of the described analysis of dynamic resistance to the impact of mining tremors are representative existing objects located in Poland. They were selected from all atypical objects located in the area subject to the impact of the planned exploitation of hard coal by mines in Upper Silesia. The selection was made in such a way as to present the specifics of the procedure for determining dynamic resistance. Not without significance were: the age of the object, the universality of the structure occurrence in the analysed area and its purpose. Selected existing bridges were marked as:

A-reinforced concrete road viaduct about $45 \mathrm{~m}$ long, over a railway line.

$\mathrm{B}$ - steel railway viaduct over a river, about $27 \mathrm{~m}$ long.

$\mathrm{C}$-reinforced concrete road viaduct about $56 \mathrm{~m}$ long, over a railway line.

D-steel railway viaduct over a road, about $56 \mathrm{~m}$ long.

\section{Data on Mining Tremors Adopted in Dynamic Analyses}

One of the first important stages of the analysis of dynamic resistance of existing bridges is the collection of information on the paraseismic activity of the mining area, where the object is located. This is related to the conditions of the selected method of analysis of the load-bearing structure resistance. Due to the unusual nature of this analysis, it was first and foremost necessary to obtain accelerograms registered at measuring stations existing in the area of the location of the analysed objects.

Obtained accelerograms came from two sites located on the surface of the land. These places are located in the basements of a residential building and an outbuilding. The system of recording vibrations generated by mining tremors has been operating since August 2010. It is also known that in the previous 10 years there were no tremors with energy greater than 1.0 MJ.

The accelerograms contained data of eight actual tremors with a time step $\mathrm{dt}=0.0026 \mathrm{~s}$, recorded in three orthogonal directions. While analysing the received signals, attention was paid to: maximum horizontal acceleration, resultant acceleration at the measurement site after filtration in the $0-10 \mathrm{~Hz}$ band as well as distance between the object and the epicenter. The most intense recorded tremors from the entire period of monitoring the ground surface vibration were selected (Table 1), i.e., from August 2010. The data does not include measurements, as well as estimates of peak accelerations in the epicentral zone.

Generally, when assessing the usefulness of the compiled data for the numerical analysis of objects, it should be stated that the tremors are of low intensity, and therefore, only three out of eight were selected for further calculations. These were designated as Z107, Z137 and P6 and with the maximum actual horizontal acceleration of 201, 148 and $155 \mathrm{~mm} / \mathrm{s}^{2}$. Graphical presentation of time-varying acceleration has been compiled in Figs. 1-2 which correspond to the order number of tremors.

The listed accelerograms (Figs. 1, 2, 3) were selected from those available as kinematic excitations of the numerical model. Adoption of the optimal signal will finally make it possible to achieve the lowest dynamic resistance of the analysed object, and thus ensure the safety of the structure. The optimal signal should be considered the one which has the highest intensity and time-spectral properties that harmonize with the modal characteristics of the analysed object. Fulfilling these demands guarantees an extreme dynamic response of the object. From a practical point of view, the most important element of the analysis is the correct selection of signals, due to the time-spectral properties that resonate with the viaduct model. The use of signals recorded in the area, where the analysed object is located makes the occurrence of tremors with similar characteristics more realistic. In turn, this makes the procedure of determining dynamic resistance more realistic.

Each signal was subject to an independent assessment as to its usefulness due to:

- acceleration peak values,

- duration,

- spectral characteristics using the Gabor transform. 
Table 1 Values of energy, distances and accelerations of mining origin recorded on the surface of the land

\begin{tabular}{llllcc}
\hline No & Data of tremors & Seismic energy $[\mathrm{kJ}]$ & Epicentral distance $[\mathrm{m}]$ & \multicolumn{2}{c}{ Maximum horizontal acceleration $\left[\mathrm{mm} / \mathrm{s}^{2}\right]$} \\
\cline { 3 - 5 } & & & After filtration & Without filtration \\
\hline 1 & 28.08 .2010 & 75 & 504 & 53.4 & - \\
2 & 24.11 .2010 & 95 & 852 & 28.6 & 148 \\
3 & 15.03 .2011 & 97 & 482 & 110.4 & - \\
4 & 22.03 .2011 & 89 & 530 & 35.9 & - \\
5 & 11.04 .2011 & 63 & 1084 & 52.1 & 155 \\
6 & 12.04 .2011 & 270 & 550 & 159.6 & 201 \\
7 & 31.05 .2012 & 820 & 1029 & 44.2 & - \\
8 & 07.06 .2012 & 960 & 1001 &
\end{tabular}

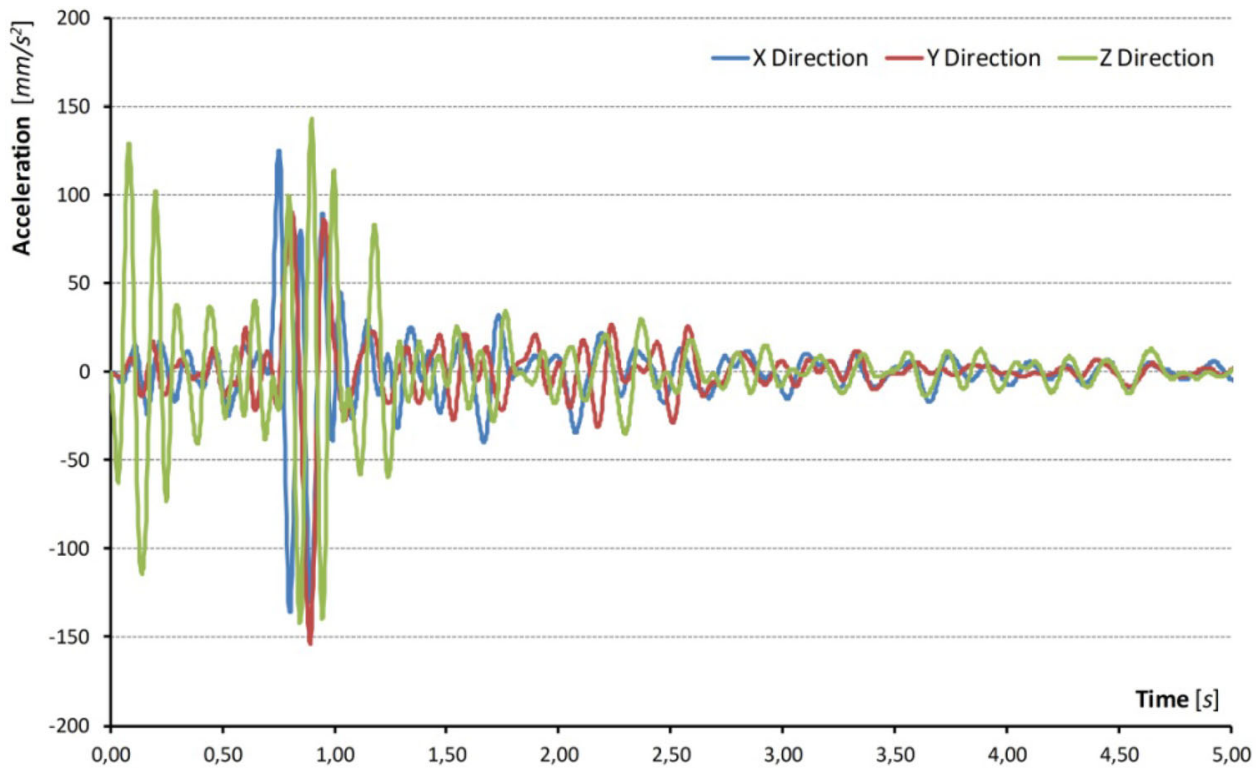

Fig. 1 Course of acceleration of land in three directions, recorded as Z107

In general, the Gabor transformation [16] can be defined as the representation of a non-stationary signal in the form of the sum of base functions. They arise from the assumed prototype function as a result of its movement along the time and frequency axis, by multiplying complex harmonic signals. The time-frequency Gabor transformation of the continuous signal $x(t)$ is defined by the formula:

$x(t)=\sum_{m, n=-\infty}^{+\infty} c_{m, n} g_{m, n}(t)$,

where

$g_{m, n}(t)=g(t-m \cdot \Delta t) e^{j 2 m \Delta f \cdot t}, \Delta t \cdot \Delta f \leq 1$ - shifting $\quad$ in time domain by $m \cdot \Delta t$ and frequency domain by $n \cdot \Delta f$ the so-called function of the synthesis window $g(t)$ with energy equal to one,

$\Delta t, \Delta f$-preset shift in time and frequency domain, respectively.
The synthesis window should be characterized by a concentration of energy in both domains. Practically, this means that it is compact, i.e., has a narrow base. This ensures good resolution of the signal synthesis and the accuracy of results. Represented in the form of changes in the spectral and time properties of the tested signal (Fig. 3). Usually a Gaussian window is used, because it can be narrowed and expanded depending on the needs and computational conditions, primarily from the period of discretization of the analysed signal.

Gabor transformation decomposition coefficients are calculated from the signal using the so-called analysis window function $\gamma(t)$ :

$c_{m, n}=\int_{-\infty}^{+\infty} x(t) \gamma_{m, n}^{*}(t-m \cdot \Delta t) \cdot e^{j 2 m \cdot \Delta f \cdot t}$. 


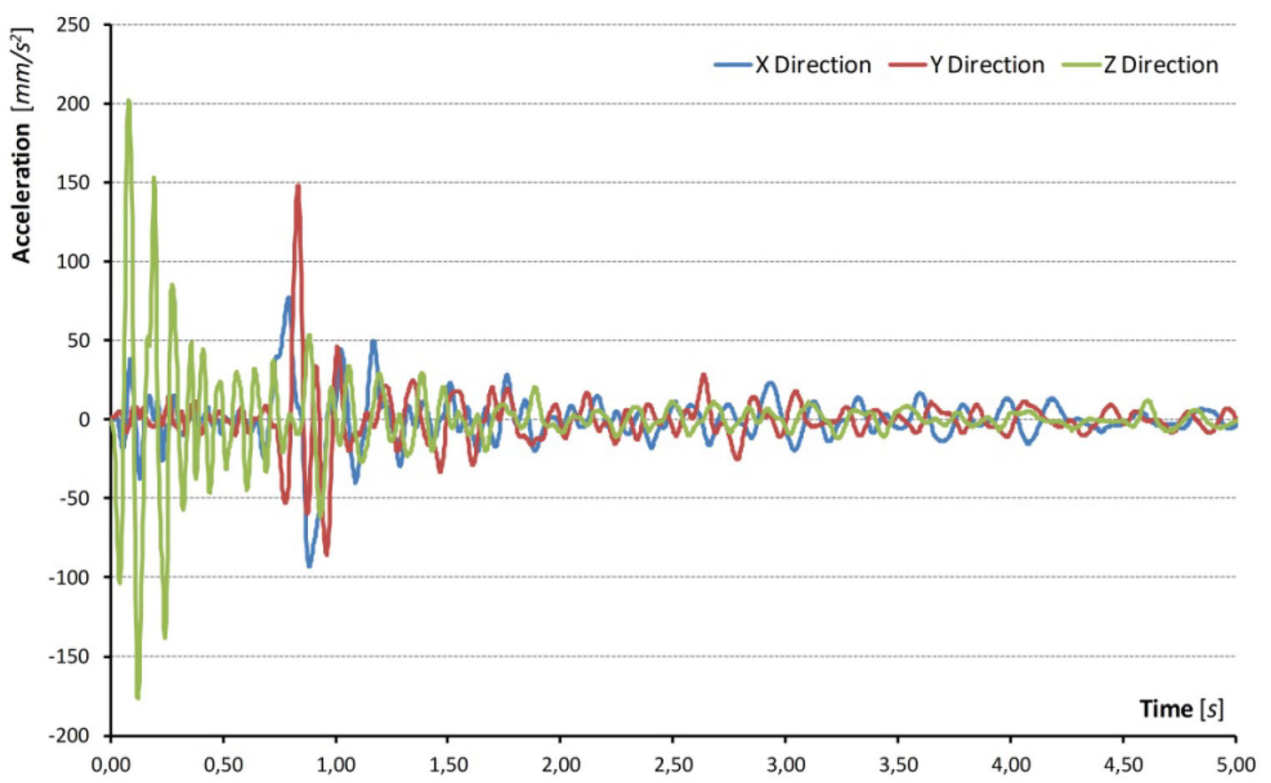

Fig. 2 Course of acceleration of land in three directions, recorded as Z137

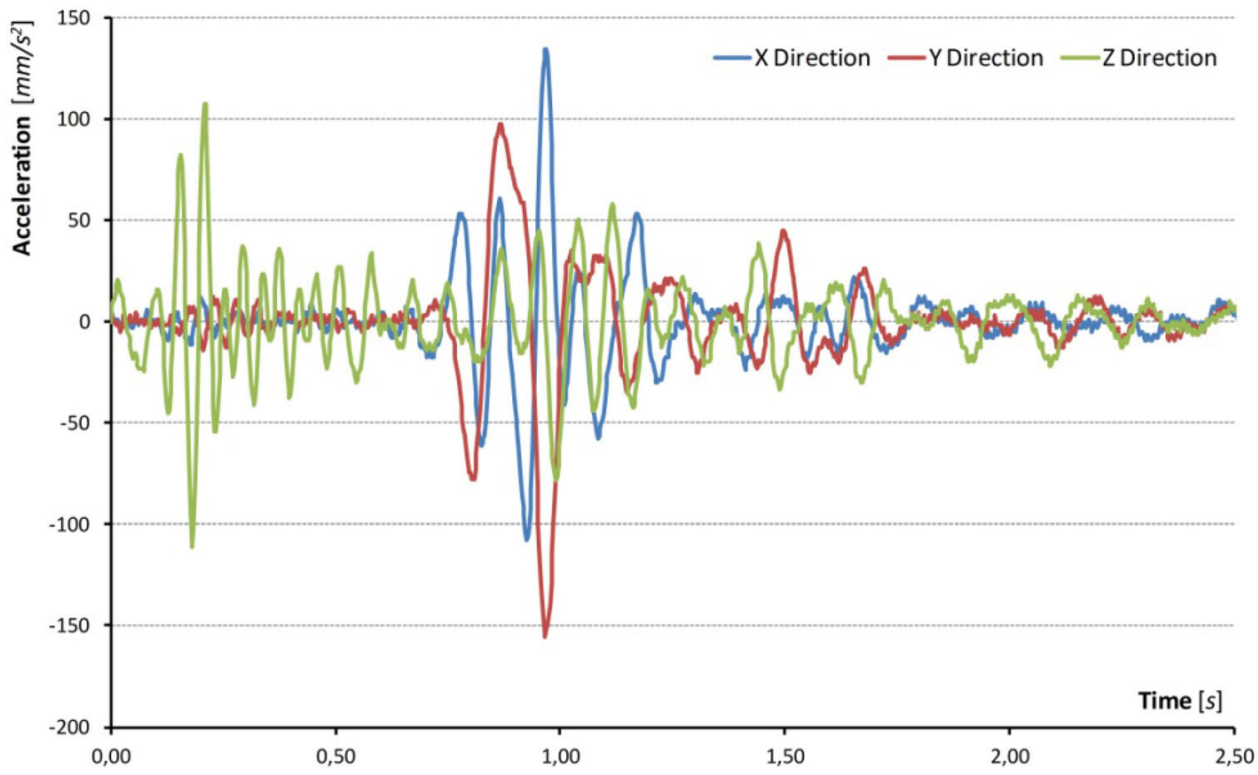

Fig. 3 Course of acceleration of land in three directions, recorded as P6

This function (2) is associated with the synthesis function (1), because it is biorthogonal to it (complex conjugate function). This means that it is simultaneously orthogonal in time and frequency domain, which is expressed by the formula:

$\sum_{m, n} g_{m, n}(t) \gamma_{m, n}^{*}\left(t^{\prime}\right)=\delta\left(t-t^{\prime}\right)$

When analysing one signal, the same analysis window is used, which moves along the signal in the time domain. In this way, the values of the coefficients are obtained in different points on the plane defined by the time and frequency axes.

The Gabor transform modules, i.e., the resulting timefrequency representations of Gabor, i.e., the equivalents of spectral power density, but calculated simultaneously in both time and frequency domains, are determined by the formula:

$S_{x}(m \cdot \Delta t, n \cdot \Delta f)=\left|c_{m, n}\right|^{2}$.

By analogy with the Fourier transform, function (4) can be interpreted as spectral power density. 
Formulas (1) and (2) also have a discrete version. It was implemented using a script written in the Matlab environment. Chebyshev polynomials showing energy concentration around the central frequency and minor errors related to the so-called side leaves adopted as a synthesis window. An example of a solution to this task is a map in the frequency and time structure, which is presented in Fig. 4. The dominant frequencies in the Z107 signal in the $\mathrm{Y}$ direction (placed on the map as an overview) are marked in a dark colour. Significant signal frequencies in this direction are located between 0.75 and $1.00 \mathrm{~s}$ of their duration and take values between 4 and $8 \mathrm{~Hz}$. Similar analyses were carried out for all signals included in the study.

According to the current prognosis regarding the impact of mining tremors on surface objects, acceleration values from 110 to $230 \mathrm{~mm} / \mathrm{s}^{2}$ were predicted (by the mining plant) depending on the location of the object and the mining area. In this study, $270 \mathrm{~mm} / \mathrm{s}^{2}$ is assumed as the extreme boundary acceleration forecasted for the analysed objects. This approach allows to safely determine the resistance of an object assuming possible differences in the prognosis.

\section{Technical Description of the Analyze Bridges}

\subsection{Description of the Road Viaduct-A}

The viaduct (Fig. 5) was built in 1952. It is located in the area of Upper Silesia. It enables passage over a twotrack railway line. The building has a monolithic reinforced concrete supporting structure in the form of a three-span frame with theoretical spans of 13.75-18.55-13.40 m. The viaduct crosses the railway tracks at an angle of $79.5^{\circ}$. This is also the slant of the span and supports relative to the span. The superstructure of the viaduct platform is a reinforced concrete slab, based on five continuous support beams. Beam spacing is $1.44 \mathrm{~m}$. Their cross-section is $1.05 \mathrm{~m}$ high and $0.55 \mathrm{~m}$ wide, which is increased in the support area on the frame pillars. On both sides of the road, cantilever pavement slabs, with a projection of $1.80 \mathrm{~m}$ beyond the face of the extreme support beams, were made. The platform width is $9.92 \mathrm{~m}$ and its length is $46.35 \mathrm{~m}$. The viaduct is supported by two monolithic frame pillars with five posts each, founded on a foundation footing. Abutments were also made as monolithic, full-walled, with wings located parallel to the road. The beams were based on abutments via slip layers. The facility was not designed with mining loads taken into account. In addition, mining tremors were also not considered. Currently, the object has undergone renovation together with the strengthening of support columns. The article analyses the object's prestrengthening resistance.

\subsection{Technical Description of the Railway Viaduct-B}

The facility is located on the railway line above the stream and road. This line has two independent tracks, and therefore, the object consists of two independent viaducts:

the older one, erected in 1946 under one track, located on the west side,

the newer one from 1973, under the second track, located on the east side.

Each of the viaducts has two spans and is structurally independent of the other (Fig. 6). The choice of the older bridge structure was dictated by the greater span length and

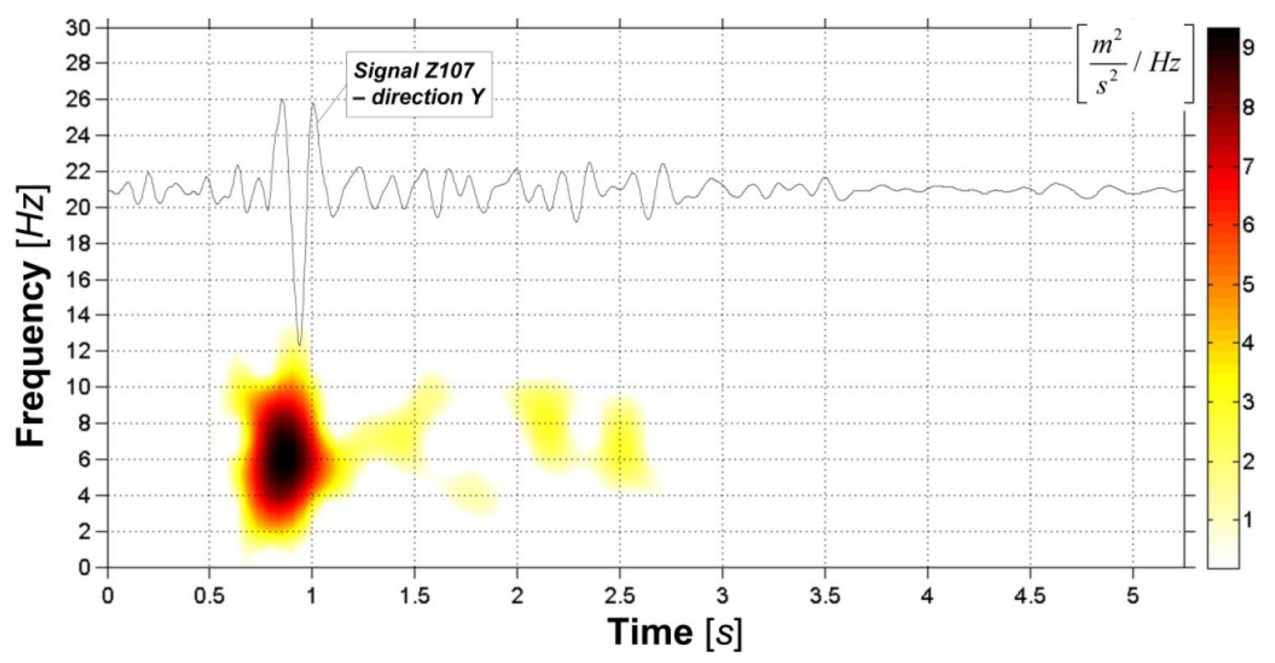

Fig. 4 Modules spectrum of Gabor transformation paraseismic signal Z107 Y-description in the text 


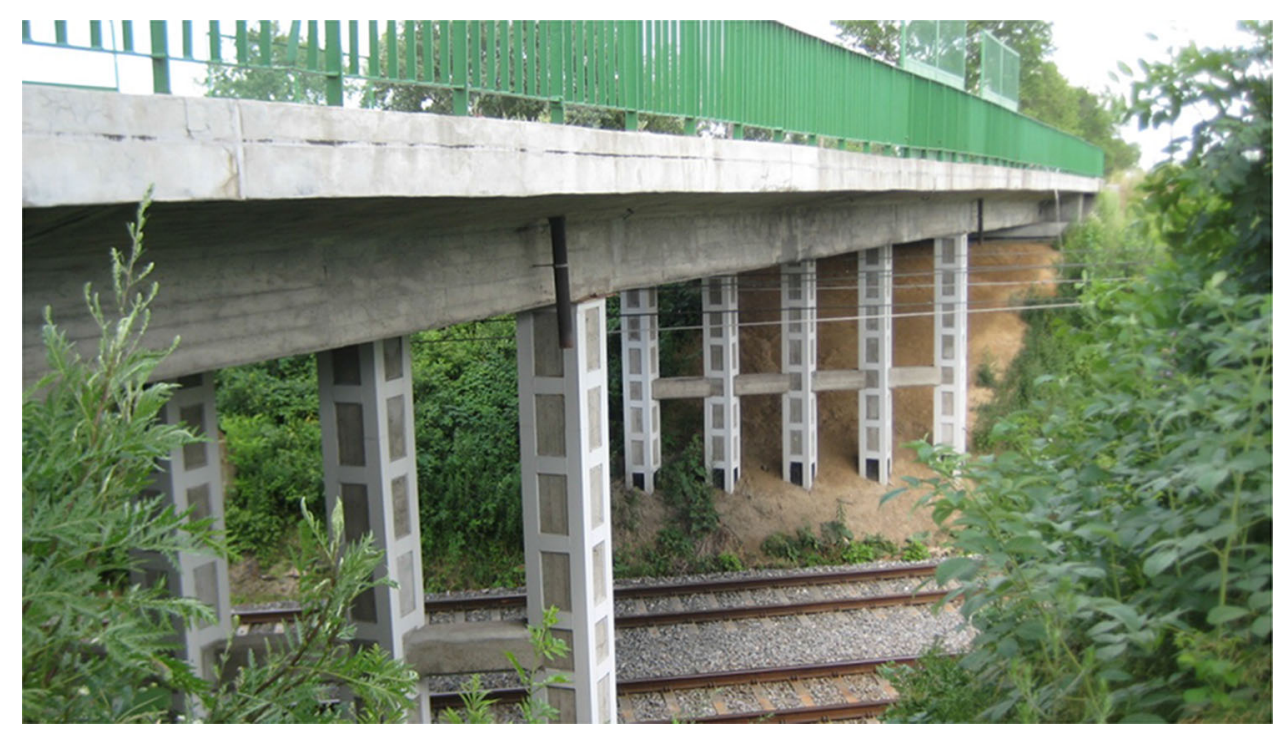

Fig. 5 View of the road viaduct $\mathrm{A}$-photo taken after strengthening and renovation of the object

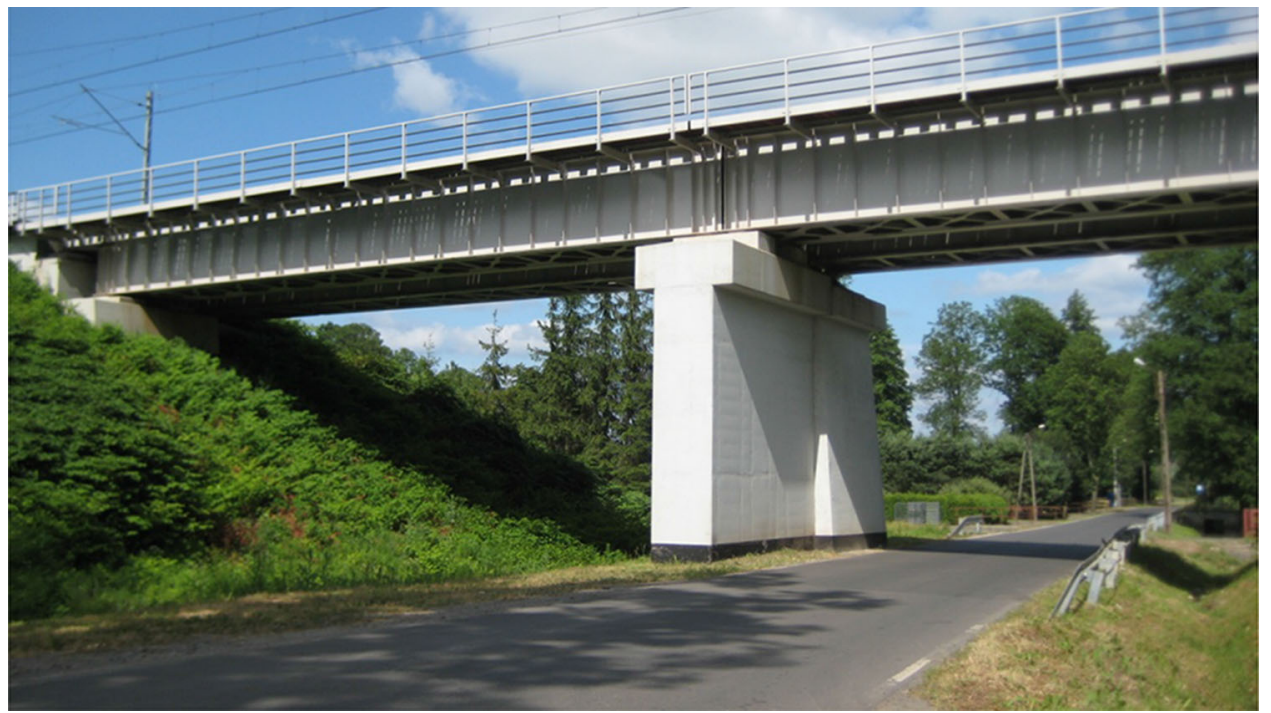

Fig. 6 View of the railway viaduct B-photo taken after renovation of the object

its total mass, which contributes to more intense impacts of tremors.

The eastern viaduct has two spans, each of which is a free-supported steel plate girder with upper travel, with a theoretical span of $26.88 \mathrm{~m}$. The transverse spacing of the main beams is $2.20 \mathrm{~m}$. They are connected with transverse bracing, every $1.92 \mathrm{~m}$. Plate girders with a cross-section height of $2.32 \mathrm{~m}$ were welded. The upper and lower belt consist of a flat bar with cross-sectional dimensions of $400 \times 60 \mathrm{~mm}$, and the web is made of $16 \mathrm{~mm}$ thick sheet metal. Local web stability is provided by welded vertical ribs every $1.92 \mathrm{~m}$. The transverse bracing was made of double angle brackets welded to the ribs. Wind transverse bracings were made from the same angles at the level of the upper and lower belts of plate girders. Sidewalk brackets with a projection of $1.6 \mathrm{~m}$ were attached to the external ribs on the eastern side. The bridge sleepers are set on the upper belts of the girders.

Reinforced concrete east viaduct supports were built by extending the existing western supports of the viaduct. The new abutments were located directly on the existing ones with a retraction of about $3 \mathrm{~m}$ towards the embankment. The pillar was added to the existing object with the same dimensions in the longitudinal direction of the object. The total dimensions of the existing pillar are $8.7 \times 1.6 \mathrm{~m}$ at the top of the section and $10.3 \times 2.6 \mathrm{~m}$ at the base of the cross section. 
Viaduct girders were based on a pillar with fixed hull bearings. On the abutments there are single-direction sliding bearings, of a double-shaft design. The eastern viaduct has lateral expansion joints on the pillar and abutments.

The facility was not designed with taking possible paraseismic loads into account.

\subsection{Description of the Road Viaduct-C}

The supporting structure of the road viaduct over the railway line consists of three freely supported spans with a grid and plate structure. The theoretical lengths of the spans are $14.10 \mathrm{~m}, 17.00 \mathrm{~m}$ and $13.75 \mathrm{~m}$. The total length of the supporting structure is $46.9 \mathrm{~m}$. The total length of the viaduct, including the abutments is $55.95 \mathrm{~m}$. Abutments and pillars were made as reinforced concrete, monolithic. The grate of each span has four load-bearing beams with a cross section of $0.45 \times 1.30 \mathrm{~m}$, with an axial spacing of $2.10 \mathrm{~m}$ and five crossbars with a cross section of $0.25 \times 1.10 \mathrm{~m}$. Spacing of the crossbars in the middle span is $4.55 \mathrm{~m}, 2 \times 4.20 \mathrm{~m}$ and $4.45 \mathrm{~m}$. The total length of the middle span is $17.62 \mathrm{~m}$, and its total width is about $9.35 \mathrm{~m}$. The platform plate of the viaduct has a thickness of $0.20 \mathrm{~m}$. The expanse of the pavement supports with cornices is $1.30 \mathrm{~m}$. The viaduct has a bituminous roadway which is $6.00 \mathrm{~m}$ wide and two pavements with the width of $1.05 \mathrm{~m}$ and $1.50 \mathrm{~m}$. Expansion joints on the viaduct are made over intermediate supports and abutments. The object's bearings are steel and roller made of single shafts with a diameter of $160 \mathrm{~mm}$.

\subsection{Technical Description of the Railway Viaduct-D}

The steel railway viaduct over the two-lane road was constructed as a single-span structure with a theoretical span of $22.7 \mathrm{~m}$. The total length of the bridge together with the abutments is $56.5 \mathrm{~m}$. There is one railway track on the bridge structure, the axis of which crosses the support axis at the abutment at an angle $49^{\circ}$. In the cross section, the bridge is a system of two I-ribbed girders with a height of $2.0 \mathrm{~m}$ each. The upper and lower flange of the welded plate girder are $600 \times 25 \mathrm{~mm}$ rectangles in cross section. A steel web is located between them with a cross section of $15 \times 1950 \mathrm{~mm}$, which local stability is ensured by a system of welded vertical ribs spaced every $1.5 \mathrm{~m}$. A steel beam pavement structure with a $1.6 \mathrm{~m}$ reach has been attached to the outside of the main girders. There is a reinforced concrete abutment with transverse dimensions of $5.4 \times 2.0 \mathrm{~m}$ at the bearing location and $7.4 \times 2.0 \mathrm{~m}$ at direct foundation. There are fixed bearings on one of the abutments and one multi-directional sliding on the other.
This is where the supporting system in the form of two plate girders is based.

\section{Assumptions and Data for Models and Numerical Calculations of Selected Bridges}

The analysis of this dynamic resistance was carried out in a unique computational situation assuming that the paraseismic load is distinct. The following assumptions resulted from the analysis:

- analogy between unique computational situations with paraseismic and seismic loading,

- taking into account the almost constant variable load value in the combination,

- forgoing the effects of wind and snow on the analysed object.

The unique combination according to Eurocode accepts in the analysed case:

$\sum_{j} G_{k, j, \text { sup }}+\sum_{i} \psi_{2, i} Q_{k, i}+A_{d}$

where

$G_{k, j}$-unfavourable values of permanent loads on the structure,

$\psi_{2, i}$-nearly constant value variable load factor,

$Q_{k, i}$-characteristic value of the variable load,

$A_{d}$ - the calculated value of the unique load generated by mining tremors.

The basic premise for using in the analyses only of the values of almost constant variable (utility) loads results from the fact that the probability of paraseismic load of extreme intensity, i.e., from regional tremor in the mining area, coinciding with the maximum possible load of the viaduct resulting from road or rail traffic is very low. The estimated period of occurrence of a significant (causing significant response of the object) excitation is up to several years. In addition, the duration of this interaction with extreme intensity is no more than a few seconds (which is confirmed by Figs. 1-2), and the accumulation time of extremely intense car or rail traffic on the viaduct span certainly is not longer than a few minutes. This fact results from field observations of traffic on the analysed objects. This approach seems to be fully justified, and therefore, it has been implemented. As a result, the coefficients of almost constant values of major mobile interactions were adopted as $\psi_{2,2}=0$.

Permanent, variable and movable loads were taken from the bridge design and supplemented with standard values. The masses distributed in each model were calculated in accordance with the principles of conducting paraseismic 
analyses, i.e., they result from the characteristic values of permanent object loads and the fact that the almost constant (long-term) part of the moving load is zero.

Considering the above, it was assumed that independent model calculations were necessary:

1. Static analysis including permanent and variable loads (including moving loads) in the basic combination.

2. Modal analysis taking into account the real rigidity of structural elements and masses attributable to these elements.

3. Dynamic analysis (THA) allowing for real signals excluding constant, variable and moving loads.

In the numerical analyses, spatial structural calculation models were used by means of the Finite Element Method (FEM) implemented in ABAQUS software. Each bridge model reflects the geometry and the load-bearing system using the structural elements listed in the technical description. The elastic work of materials (steel and concrete) was adopted in all models. The boundary conditions at the point, where the supporting elements were supported on the abutment or pillar took into account the actual bearings used (freedom of movement was defined). The presented cases have the abutment supported on the foundations piles. The dynamic signal is applied to the supports as kinematic displacement over time. This simplification causes not consider the ground stiffness and damping.

\section{Descriptions of Models and Data for Numerical Simulations}

\subsection{Model and Data for Numerical Calculations-A}

The spatial numerical model used in the calculations was based on the FEM method. It consisted of 14,000 shell and bar finite elements with a side dimension of approx. $0.2 \mathrm{~m}$. It was assumed that the columns in the foundation footing were fixed and the beams rested on the abutments on the contact layer with a friction coefficient of 0.5 . The model view is shown in Fig. 7.

Permanent, variable and movable loads were taken from the bridge design and supplemented with standard values. The masses distributed in the model were calculated in accordance with the principles of conducting paraseismic analyses:

- the distributed mass of the main beam with the associated part of the slab and topcoats is $13460 \mathrm{~kg} / \mathrm{lm}$,

- the distributed pavement mass with surface is $1820 \mathrm{~kg} /$ $\operatorname{lm}$.
Data characterizing of the construction materials was taken from the building design:

- concrete class $\mathrm{C} 16 / 20$ and $f_{\text {cd }}=8.00 \mathrm{MPa}, f_{\text {ctd- }}$ $=0.73 \mathrm{MPa}, E_{\mathrm{cm}}=27.0 \mathrm{GPa}$,

- main reinforcing steel and stirrups A-I St3SX-b and $f_{\mathrm{yk}}=240 \mathrm{MPa}, f_{\mathrm{yd}}=210 \mathrm{MPa}, f_{\mathrm{tk}}=310 \mathrm{MPa}$.

The values of internal quantities in the critical crosssections of the main beam from self-load and useful load were taken from the design calculations. In addition, the design load-bearing capacity of these cross-sections due to bending and shear calculated according to standards was also taken from the design calculations. They are associated with the following loads on the main beams in static analysis:

- a design constant load evenly distributed with intensity $36.61 \mathrm{kN} / \mathrm{m}$,

- a computational variable load with intensity $4.35 \mathrm{kN} / \mathrm{m}$,

- an equivalent mobile load with a calculated value of $58.8 \mathrm{kN} / \mathrm{m}$, distributed over a $4.5 \mathrm{~m}$ length, symmetrically distributed over the central span.

\subsection{Model and Data for Numerical Calculations-B}

In the numerical calculations, the spatial viaduct calculation model using FEM was used. It included structural elements of the object, i.e., main beams, transverse and wind bracing as well as stiffening ribs in the scope of elastic work of the material. The model uses square shell finite elements (side dimension $0.15 \mathrm{~m}$ ) in plate girder and bar in concentrations. The total number of finite elements (shell and bar) was over 5000. The view of the model is shown in Fig. 8.

The calculations took into account the viaduct loads, among others the distributed mass of the main beam with the associated part of secondary elements and track structure as $1550 \mathrm{~kg} / \mathrm{lm}$.

The following loads were applied to the main beams of the object:

- a design constant load evenly distributed with an intensity of $21.49 \mathrm{kN} / \mathrm{m}$,

- an equivalent variable load with an intensity of $80.6 \mathrm{kN} / \mathrm{m}$,

- an equivalent load with a calculated value of $157.2 \mathrm{kN} /$ $\mathrm{m}$, distributed over a $6.4 \mathrm{~m}$ length, symmetrically distributed over the central span.

The supporting structure of the viaduct was made of St3 steel, characterized by the longitudinal deformation module $E=205 \mathrm{GPa}$, Poisson's ratio $v=0.3$ and computational strength $f_{\mathrm{d}}=190 \mathrm{MPa}$. 


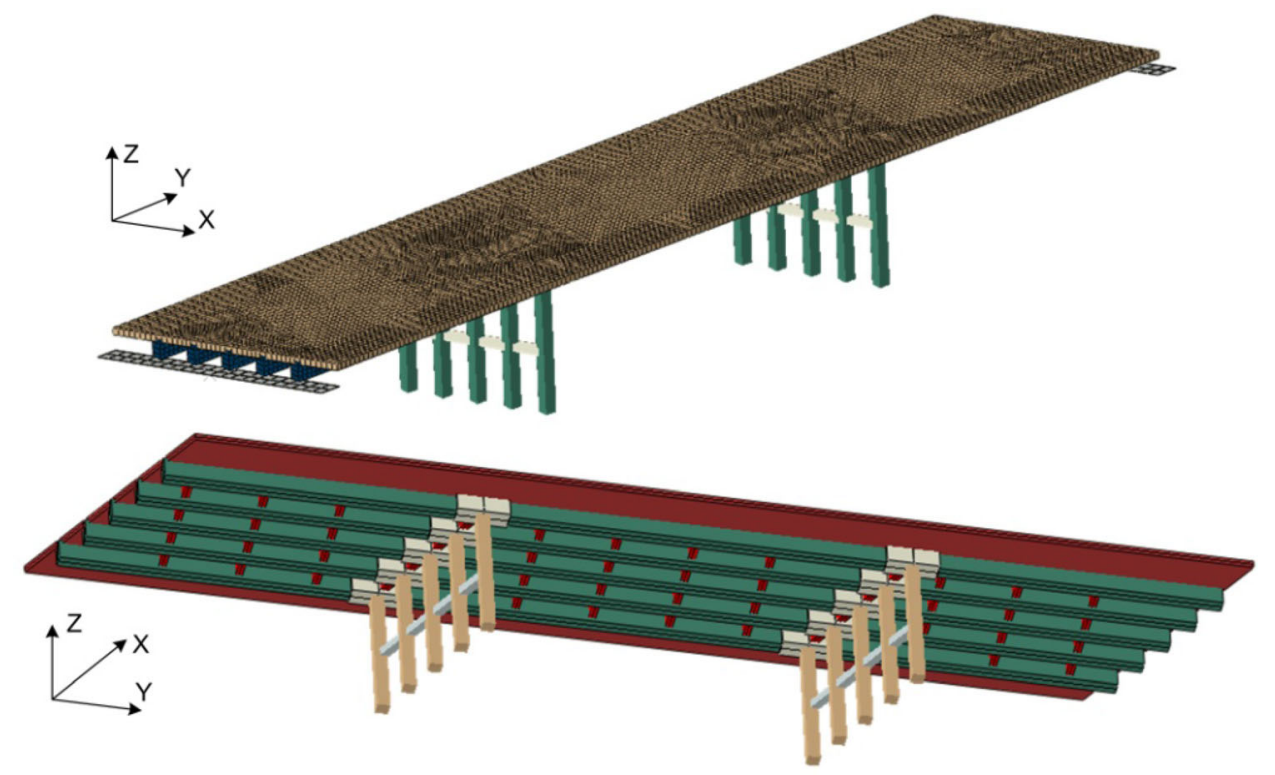

Fig. 7 View of the numerical A model of the concrete viaduct, including division into finite elements

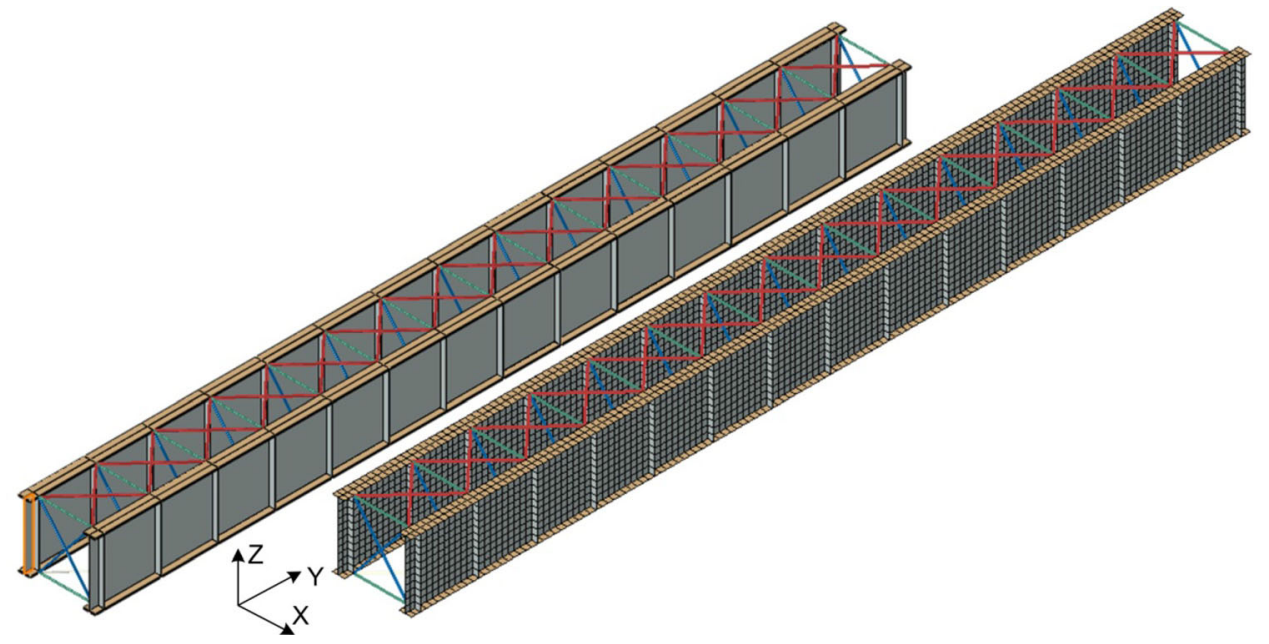

Fig. 8 View of the numerical B model of the steel viaduct, including division into finite elements

\subsection{Model and Data for Numerical Calculations-C}

The spatial calculation model of the concrete viaduct was used in the numerical calculations. Over 8 thousand quadrangular finite elements of the shell type with dimensions of about $0.25 \times 0.25 \mathrm{~m}$ were used in it. The following values of the $\mathrm{C} 16$ / 20 viaduct structural concrete were adopted:

- the elasticity modulus of concrete $E_{\mathrm{cm}}=27.5 \mathrm{GPa}$,

- Poisson's ratio $v=0.2$,

- the friction coefficient in the bearings perpendicular to the direction of possible travel $f=0.2$.

The view of the model is shown in Fig. 9.

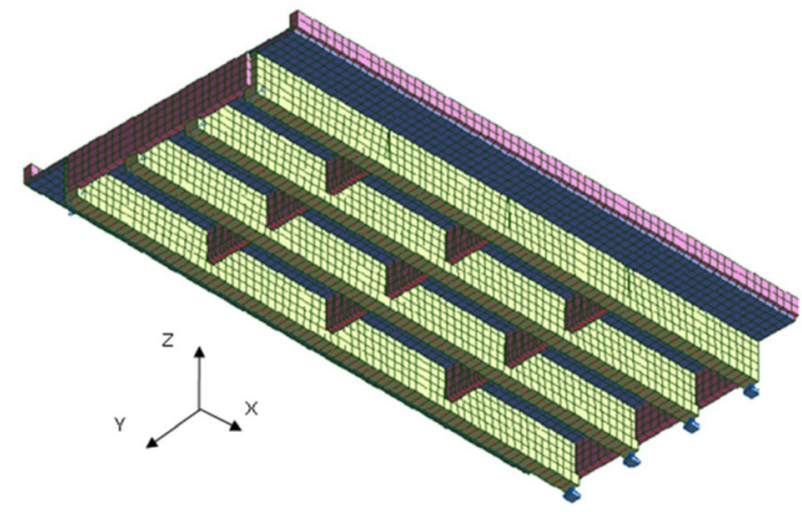

Fig. 9 View of the numerical $\mathrm{C}$ model of the concrete viaduct, including division into finite elements 
The sconcrete viaduct model was loaded statically with:

- a computational constant load uniformly distributed with intensity $27.36 \mathrm{kN} / \mathrm{m}^{2}$,

- an evenly distributed road load with calculated value $1.8 \mathrm{kN} / \mathrm{m}^{2}$,

- variable, replacement load of the roadway from a vehicle of a calculated value $30.9 \mathrm{kN} / \mathrm{m}^{2}$,

- variable load of pavements evenly distributed with a calculated value $3.25 \mathrm{kN} / \mathrm{m}^{2}$.

\subsection{Model and Data for Numerical Calculations-D}

The spatial calculation model of the steel viaduct was used in the numerical calculations. Bar and shell finite elements were used, mainly quadrangular with dimensions of about $0.25 \times 0.25 \mathrm{~m}$. This provides for a total amount of about 7 thousand elements. The view of the model is shown in Fig. 10 .

In the numerical model, in addition to the masses of load-bearing elements, substitute masses were introduced from service walkways, cantilever extensions of the main girders and tracks with equipment and the track bed. The masses have the following values for:

- pavements $-4 \mathrm{kN} / \mathrm{m}$, they are arranged in the plane of the webs of the main girders along the upper ledge, differences in values resulting from the existence of steel pipelines made under the pavement are also taken into account,

- railway tracks- $1.06 \mathrm{kN} / \mathrm{m} 2$, which is evenly distributed on the surface of the viaduct orthotropic plate, it includes tracks, fenders, wooden sleepers with washers, a layer of crushed stone and shotcrete.

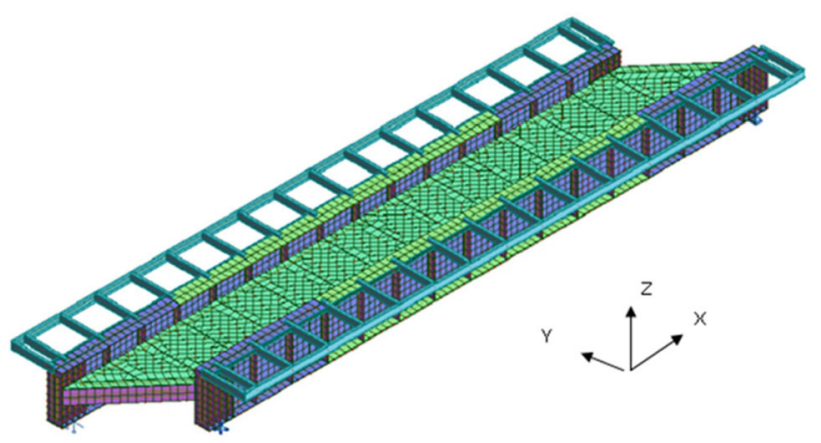

Fig. 10 View of the numerical D model of the steel viaduct, including division into finite elements

\section{Presentation of the Results of Numerical Calculations}

Calculations for each model object were carried out in stages. In the first (static) stage, the created model was subjected to constant and variable loads, including mobile interaction, in the basic combination. It is possible to omit this step in the dynamic resistance analysis using the available viaduct design calculations. According to the authors, this approach may generate differences in the level of determined resistance due to the fact that different calculation models are used. Thus, it is more advantageous to use the "own" model, and the results of static analyses obtained in this way can be referred to those contained in the viaduct design project. The second stage was a modal analysis taking into account the real rigidity of structural elements and masses attributable to these elements. The common procedure at this stage is the conversion of constant loads to masses distributed over structural elements. Performing the aforementioned postulates makes it possible to draw conclusions from the results of viaduct analyses regarding the level of projected effort (safety margin), and also, what is important, the optimal selection of the soil acceleration signal. The last stage was to conduct a full dynamic analysis (THA) with a kinematic load dependent on the actual signal. At this stage, constant, variable and movable loads were omitted.

Numerical dynamic calculations of viaduct models were carried out in accordance with the following assumptions:

- the actual stiffnesses of the structural elements together with the masses attributable to them (e.g., road surface) were taken into account,

- basic forms of natural vibrations and corresponding frequency values were sought,

- material damping with the first natural frequency were taken into account,

- the models were only subjected to dynamic loads, excluding constant, variable and movable loads,

- in the numerical calculations, time analysis (THA) was used, i.e., integration of the equation of motion by the Newmark method [14, 17, 18],

- kinematic excitations were applied, i.e., real accelerograms recorded for tremors, respectively, Z107, Z137 and P6,

- independent cases of excitation loads were simultaneously horizontal components acting on the $\mathrm{X}$ and $\mathrm{Y}$ directions, then only the vertical component and the combined action of the three components,

- on the basis of dynamic fields of normal and cutting stresses in the critical cross-sections of the viaduct's structural elements, the dynamic cross-sectional sizes and support reactions were calculated, 
- finally, from the obtained results, extreme cases were selected, which formed the basis for estimating the dynamic resistance of the object.

In the following table, the results of the dynamic analysis of the A and B bridge models are described in detail, in the case of the other models $(\mathrm{C}$ and $\mathrm{D})$ the algorithm was identical, which is why the brief versions of the results are presented.

\subsection{Analysis of the Characteristics and Dynamic Response of the Model-A}

The results of the first stage, i.e., static analysis, are the values of cross-sectional numbers resulting from the bridge design calculations, without taking into account paraseismic influences. They are summarized in Table 2. It takes into account extreme bending moments and lateral forces in the critical cross-sections of the bridge, i.e., the support zone (above the columns) and the span (in the middle of the span). These results correlate with the values included in the building design of the viaduct $\mathrm{A}$.

The numerical solution of the model in the field of modal analysis are the values of frequencies and forms of natural vibrations. Figure 11 presents three forms that determine the dynamic response of the model to kinematic excitations. The first form of natural vibrations of the presented system is displacement across the axis of the object. The second is the wave along the longitudinal axis of the object, the third figure is associated with torsion. The presented values and forms enable the proper choice of the loading direction by kinematic excitation. Having a signal with a dominant frequency around $6 \mathrm{~Hz}$ recorded in a given direction, it must be entered (in the example shown) in the direction transverse to the axis of the object. This will cause a coincidence of the natural frequency with the frequency forced by the seismic tremor, and, consequently, extreme dynamic response of the object. In specific conditions, the introduction of kinematic excitation of supports in a given direction does not have to correlate with the axial arrangement of the object, and can be rotated relative to it so that it causes an extreme response.

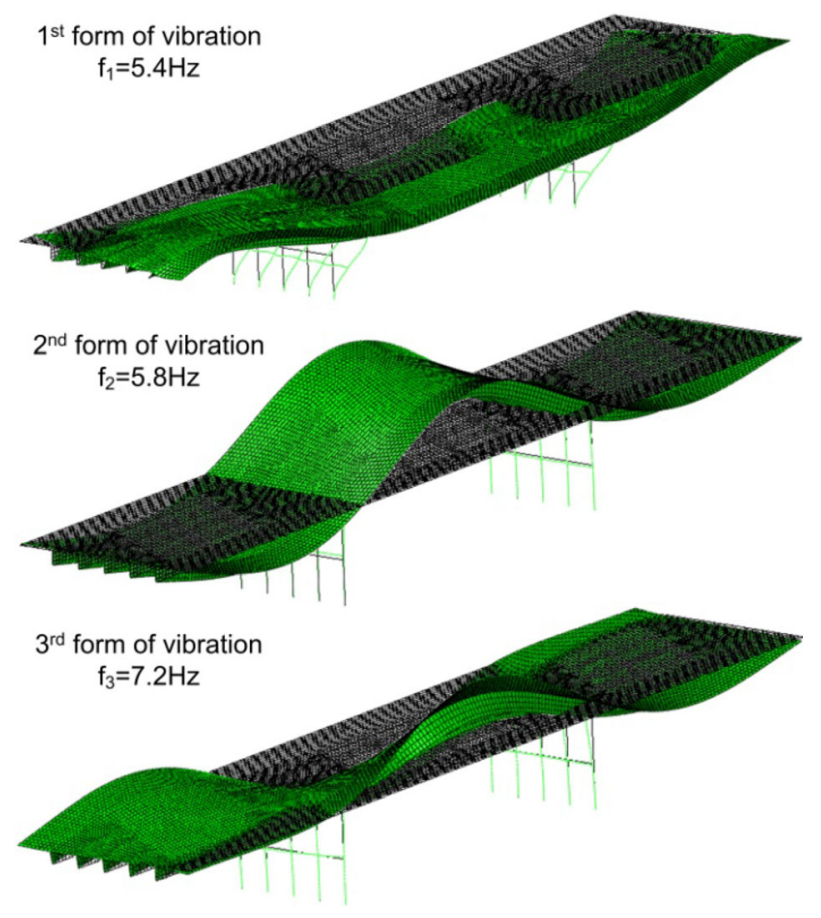

Fig. 11 Forms of vibration with the corresponding natural frequencies of A model

Figure 12 shows the time-varying course of horizontal displacements of the pillar head relative to its base, caused by the action of horizontal components of excitation by the Z137 tremor signal. The displacement value at $t=0 \mathrm{~s}$ represents the response to static load (from the masses themselves). It is worth noting that the relative values of the calculated displacements in the $\mathrm{Y}$ direction (along the object axis) are 8 times greater than those in the $\mathrm{X}$ direction (across the object axis). The Z137 signal itself (Fig. 2) has twice the intensity in the $\mathrm{Y}$ direction than in $\mathrm{X}$ direction.

Figure 13 shows maps of extreme normal stresses associated with the impact on the model of horizontal kinematic excitations resulting from the Z137 signal. The presentation was made in the structural elements of the platform slab and beams at the time corresponding to the largest displacement from Fig. 12.

Generally, it can be stated that the effect of the applied kinematic excitations on the object model in the form of displacements is insignificant. For example, the peak

Table 2 Summary of internal forces resulted from the design load—without paraseismic impact

\begin{tabular}{lllrr}
\hline No & Load & Localization of section & Bending moment $[\mathrm{kNm}]$ & Shear force $[\mathrm{kN}]$ \\
\hline 1 & Dead load & Support & 986.8 & 339.5 \\
2 & Span & 587.8 & 0.0 \\
3 & Live and mobile load & Support & 486.3 & 172.6 \\
4 & & Span & 778.6 & 0.0 \\
\hline
\end{tabular}




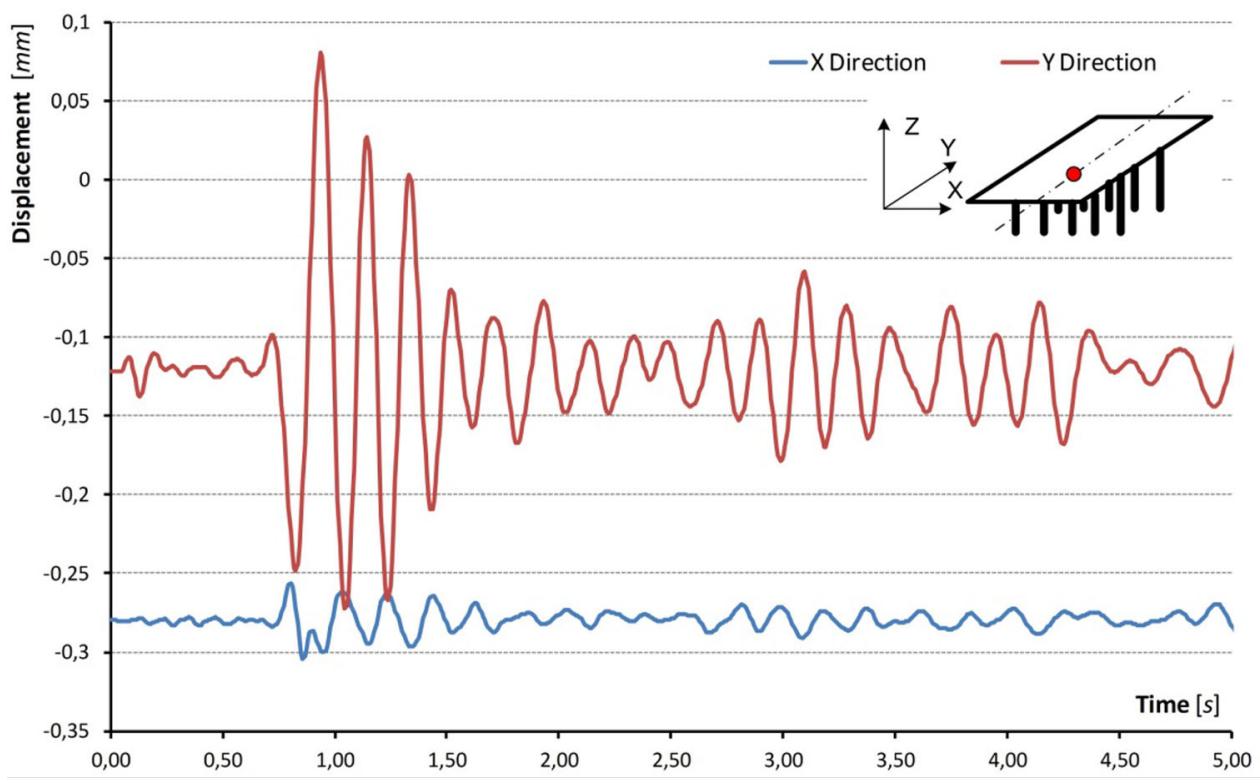

Fig. 12 Waveforms of horizontal displacement of the column head during dynamic analysis using the Z137 signal

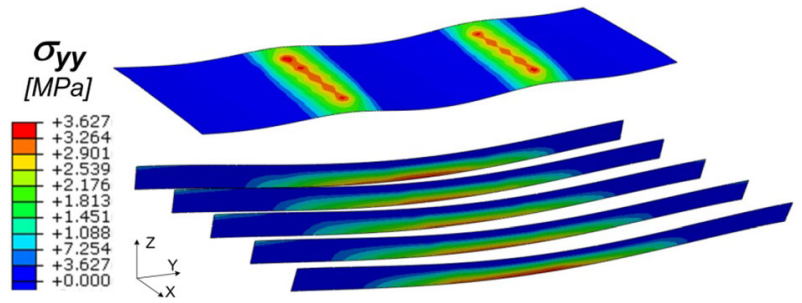

Fig. 13 Maps of dynamic tension stress $\sigma_{\mathrm{yy}}[\mathrm{MPa}]$ in main beams and platform plate A model

values of the displacement components along and across the axis of the viaduct crossover, above the pillar, do not exceed $u_{\mathrm{y}}=24 \mu \mathrm{m}$ and $u_{\mathrm{x}}=35 \mu \mathrm{m}$. Due to the high rigidity of the supporting structure, they are accompanied by large cross-sectional sizes.

\subsection{Analysis of the Characteristics and Dynamic Response of the Model-B}

The static calculations gave the values of internal quantities in the critical cross-sections of the main beam from selfload and functional loads, as well as the design loadbearing capacity of these cross-sections due to bending and shearing calculated according to standards. The figures of cross-sectional values are presented in Table 3.

Figure 14 presents three frequencies and forms of natural vibrations characterizing the numerical model of object $\mathrm{B}$, determining the dynamic response in kinematic excitation. The first form is a bending form in the $\mathrm{X}$ direction, the second in the $\mathrm{Z}$ direction, and the third is a torsional form along the $\mathrm{Y}$ axis. The presented solution is consistent with the results of tests on actual objects $[9,10]$.
Performing numerical calculations in the field of time analysis with the use of selected signals allowed for obtaining time-varying values of support reactions. Figure 15 shows the course of three translational reactions registered on the support, caused by the action of both horizontal components of excitation with the Z107 signal.

The presented results have been limited to dynamic load, and the model response is significant in the $\mathrm{Y}$ direction, i.e., along the axis of the object. This means that the bridge support parameters can determine the dynamic resistance of the object. THA (Time History Analysis) enables tracking changes in stress values in structural loadbearing elements. Figure 16 shows maps of extreme normal stresses associated with the impact on the model of horizontal and vertical kinematic excitations resulting from the use of the Z137 signal. Stress distribution maps refer to a specific time moment. In the case, where the vertical component is taken into account, stress extremes can be obtained at a completely different time moment than when this component is not taken into account. The example illustrated in Fig. 16 clearly shows the change in location of the greatest effort of the bridge structural elements.

\subsection{Analysis of the Characteristics and Dynamic Response of the Model-C}

At this point, the authors decided to present only the results of modal analysis, while all stages of model analysis were carried out in a manner analogous to previously presented cases. Figure 17 presents three forms of natural vibrations of the $\mathrm{C}$ model together with the corresponding frequency values. Due to the rigidity of the structure, the first form of 
Table 3 Summary of internal forces resulting from the design load-without paraseismic impact

\begin{tabular}{lllcl}
\hline No & Load & Localization of section & Bending moment $[k N m]$ & Shear force $[k N]$ \\
\hline 1 & Characteristic dead load & Support & - & 205.3 \\
2 & & Span & 1386.0 & - \\
3 & Design permanent load & Support & - & 253.8 \\
4 & & Span & 1712.9 & - \\
5 & Design variable load & Support & - & 1375.4 \\
6 & & Span & $10,548.9$ & - \\
\hline
\end{tabular}

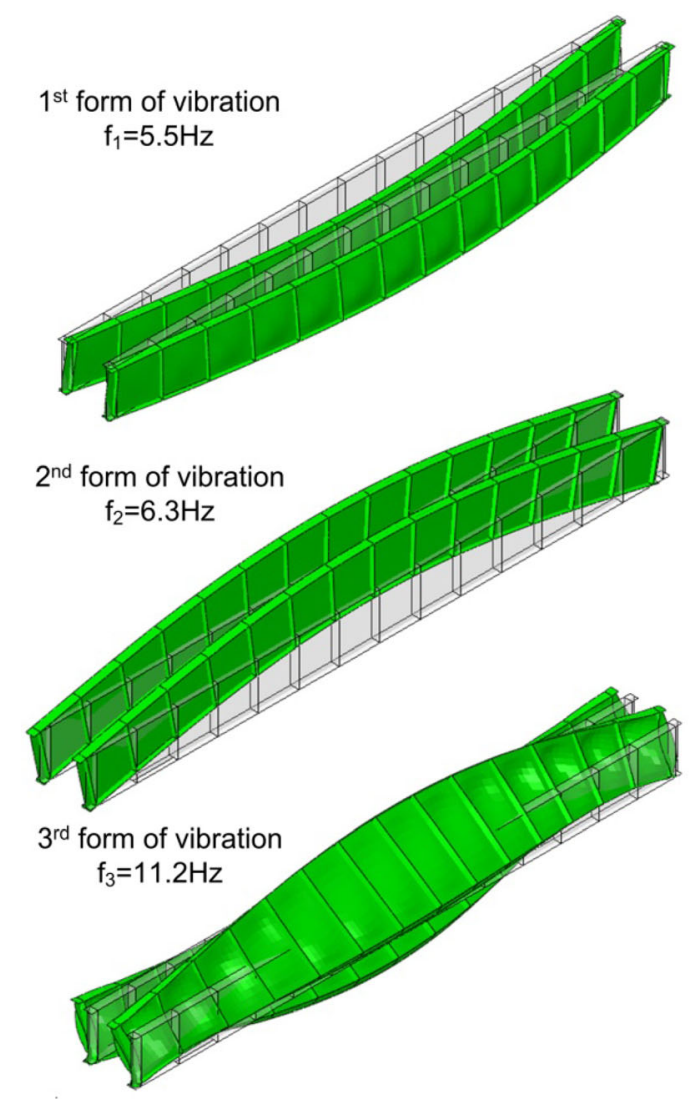

Fig. 14 Forms of vibration with the corresponding natural frequencies of B model

free vibration is characterized by a bending form in the vertical direction. The second is the torsional form along the longitudinal axis of the object, and the third is halfwave in the vertical direction.

\subsection{Analysis of the Characteristics and Dynamic Response of the Model-D}

The dynamic characteristics of the steel viaduct model are depicted in Fig. 18, which shows three frequencies and forms of free vibrations. The design of the viaduct determines subsequent forms, where the first is associated with

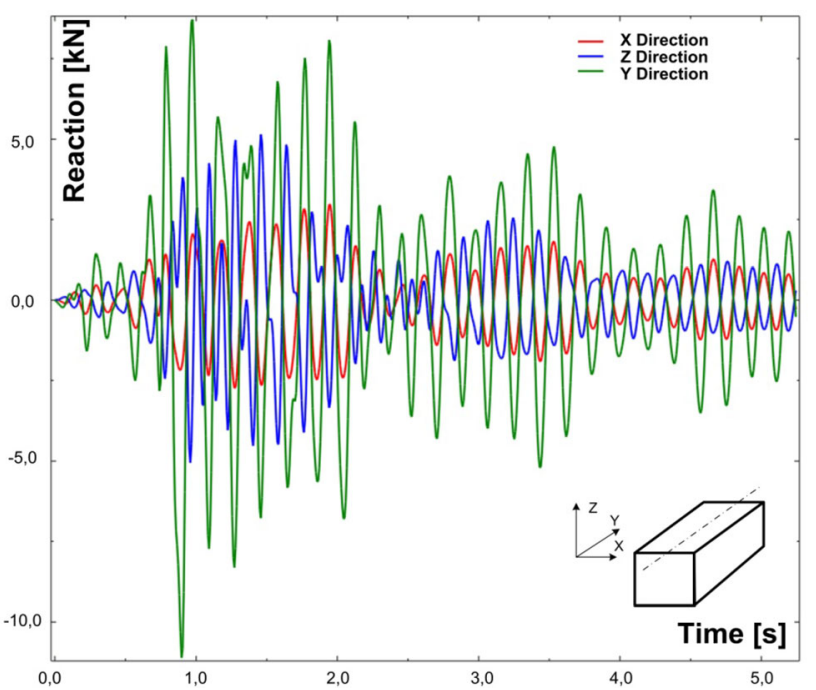

Fig. 15 Waveforms of reaction components during dynamic analysis using the Z107 signal

the bending form in the horizontal direction transverse to the axis of the object. The second is the bending form in the vertical direction and the third is the torsional form along the longitudinal axis of the object.

It is worth noting that in the solutions of all the analysed viaduct models, regardless of the material from which they are made, the natural frequency of the bending form in the vertical direction was 5.3-6.3 Hz. In the subsequent part of the article, the method of determining the dynamic resistance of the viaduct is presented with the examples of models A and B.

\section{Specification for Determining the Dynamic Resistance of Existing Bridge}

The resistance of the supporting structure of the viaducts to the impact of mining tremors was determined by performing an exceptional form of calculation. The loads were, therefore, set according to the unique combination, in the form known as EC (Eurocode). 

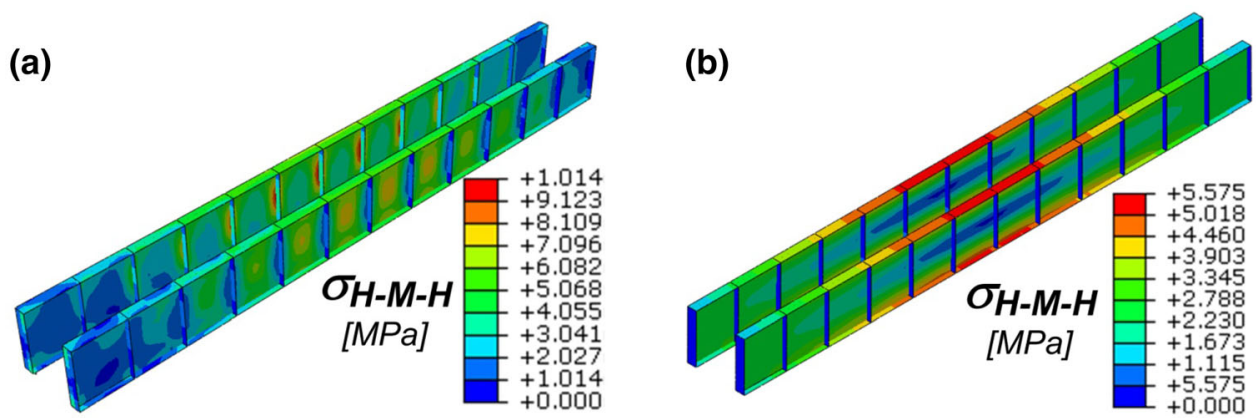

Fig. 16 Maps of reduced stress associated with (a) horizontal components of impact, (b) vertical component

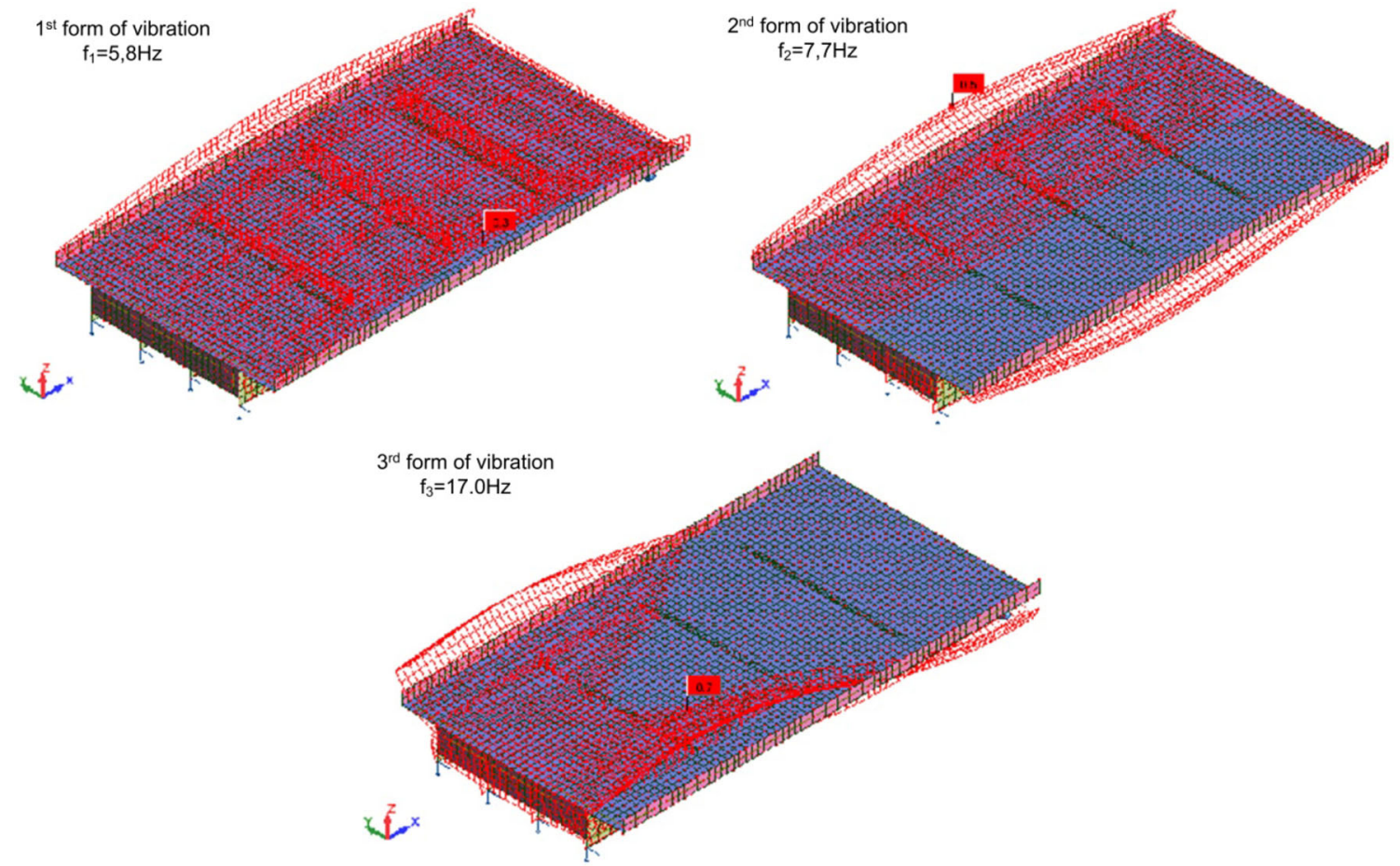

Fig. 17 Forms of vibration with the corresponding natural frequencies of $\mathrm{C}$ model

Taking this combination into account (5), together with the simultaneous application of cross-sectional forces and cross-sectional load capacity of the critical structural elements (due to bending and shear), the structure resistance to the impact of mining tremors can be estimated according to the following relationship (6):

$$
\begin{aligned}
a_{0, \max } & =\min \left\{a_{\max } \cdot \frac{R_{d}-E_{d, \text { stat }}}{E_{d, d y n}}\right\} \\
& =\min \left\{a_{\max } \cdot \frac{R_{M, d}-M_{d, \text { stat }}}{M_{d, d y n}}, a_{\max } \cdot \frac{R_{V, d}-V_{d, \text { stat }}}{V_{d, d y n}}\right\},
\end{aligned}
$$

where
- $R_{\mathrm{d}}, R_{\mathrm{M}, \mathrm{d}}, R_{\mathrm{V}, \mathrm{d}}$-design load capacity of the critical section, in general: due to bending moments and lateral forces, respectively,

- $E_{\mathrm{d}, \mathrm{stat}}, E_{\mathrm{d}, \mathrm{dyn}}$-values of computational effects impact,

- $M_{\mathrm{d}, \mathrm{stat}}, M_{\mathrm{d}, \mathrm{dyn}}$,-design values of bending moments in critical sections, respectively: static and dynamic,

- $V_{\mathrm{d}, \mathrm{stat}}, V_{\mathrm{d}, \mathrm{dyn}}$-as above but with respect to lateral forces,

- $a_{\max }, a_{0, \max }$-values of peak accelerations caused by mining tremors, respectively: kinematic excitations and those resulting from measurements and characterizing the most intense estimated mining tremor.

The dynamic resistance method defined above was used in the analysis of the viaduct models presented. 


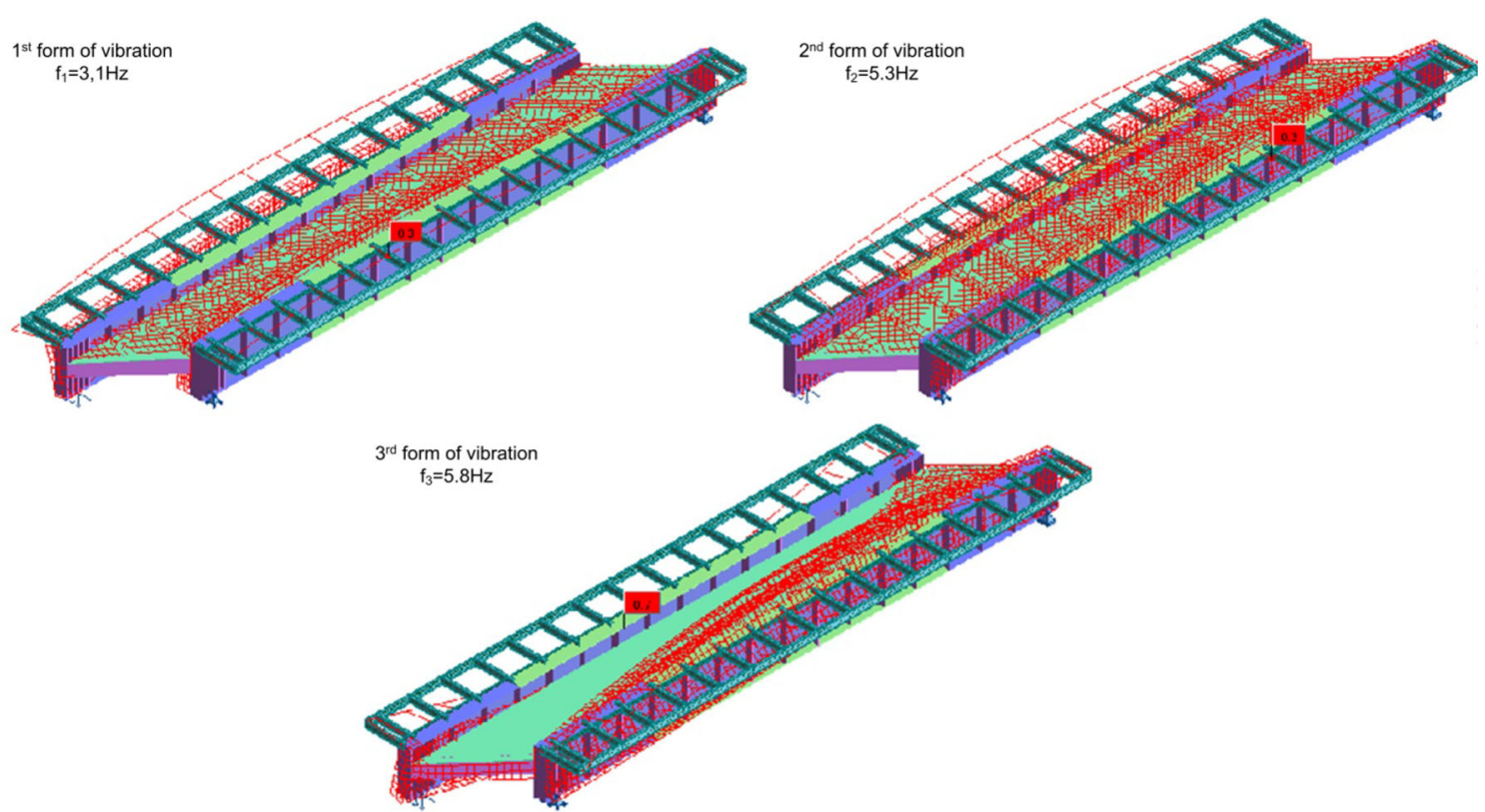

Fig. 18 Forms of vibration with the corresponding natural frequencies of D model

\subsection{Estimation of Dynamic Resistance of the Viaduct-A}

The assessment of the viaduct supporting structure resistance using bending moments and lateral forces was supplemented by checking the resistance of the bearing beams' support on the abutments due to slip. To this end, the total friction force transmitted by the beam support was estimated:

- the reaction over the abutment of a single beam according to the design is $139.14 \mathrm{kN}$,

- total friction force (10 supports) $H_{\mathrm{t}}=0.5 \cdot 10 \cdot 139.14=696.0 \mathrm{kN}$.

The results of calculations according to formula (6) are summarized in Table 4. It includes design values and those obtained from numerical calculations using three mining tremor signals.

Based on the analysis of the results of numerical calculations, it can be assumed that the resistance of the viaduct expressed by the extreme values of the resulting horizontal accelerations of the earth's surface is:

- maximum acceleration value after filtration in the $0-10 \mathrm{~Hz}$ band about $550 \mathrm{~mm} / \mathrm{s}^{2}$,

- peak acceleration actual value about $700 \mathrm{~mm} / \mathrm{s}^{2}$.

The presented results allow for the assumption that the dominant parameter determining the multitude of dynamic resistance is the object's ability to transfer horizontal forces through abutments. This approach was already suggested by the results presented in Fig. 12, where the displacement response dominated, recorded along the axis of the object.

The values of the estimated resistances of the A viaduct model are greater than the forecast that was $270 \mathrm{~mm} / \mathrm{s}^{2}$. It should be concluded that, in this case, the anticipated dynamic impacts of mining origin will not threaten the safety the bridge structure.

\subsection{Estimation of Dynamic Resistance of the Viaduct-B}

The resistance of the supporting structure of the railway viaduct to the impact of mining tremors was determined by performing an exceptional form of calculation. Loads were set according to the unique combination (5) with simultaneous application of cross-sectional forces and load-bearing capacity of critical sections, due to bending and shearing. Therefore, it is possible to estimate the resistance of the structure to the impact of mining tremors according to the relationship (6).

The assessment of the viaduct load-bearing structure resistance using bending moments and lateral forces was supplemented by checking the load-bearing system resistance to horizontal forces. For this purpose, the computational values have been determined:

- braking forces $H_{1}=208.1 \mathrm{kN}$,

- forces from side impact of rolling stock $H_{2}=150 \mathrm{kN}$.

The results of calculations according to formula (6) are summarized in Table 5. The calculation values of the loadbearing capacity of girders of the viaduct were taken from 
Table 4 Summary of numerical calculations results and design data for the viaduct A

\begin{tabular}{|c|c|c|c|c|c|c|c|c|}
\hline \multirow[t]{2}{*}{$\begin{array}{l}\text { Location of } \\
\text { section }\end{array}$} & \multirow[t]{2}{*}{$\begin{array}{l}\text { Design load } \\
\text { capacity } \\
{[\mathrm{kNm}] /[\mathrm{kN}]}\end{array}$} & \multirow[t]{2}{*}{$\begin{array}{l}\text { Combined effects of static } \\
\text { loads by unique combination } \\
{[\mathrm{kNm}] /[\mathrm{kN}]}\end{array}$} & \multirow[t]{2}{*}{$\begin{array}{l}\text { Recorded } \\
\text { signal }\end{array}$} & \multirow[t]{2}{*}{$\begin{array}{l}\text { Effects of } \\
\text { mining tremors } \\
{[\mathrm{kNm}] /[\mathrm{kN}]}\end{array}$} & \multicolumn{2}{|c|}{$\begin{array}{l}\text { Extreme horizontal } \\
\text { acceleration from } \\
\text { tremors }\left[\mathrm{mm} / \mathrm{s}^{2}\right]\end{array}$} & \multicolumn{2}{|c|}{$\begin{array}{l}\text { Resistance } \\
\text { expressed by } \\
\text { extreme horizontal } \\
\text { acceleration }[\mathrm{mm} / \\
\left.\mathrm{s}^{2}\right]\end{array}$} \\
\hline & & & & & $\begin{array}{l}\text { After } \\
\text { Filtration }\end{array}$ & $\begin{array}{l}\text { Without } \\
\text { filtration }\end{array}$ & $\begin{array}{l}\text { After } \\
\text { filtration }\end{array}$ & $\begin{array}{l}\text { Without } \\
\text { filtration }\end{array}$ \\
\hline \multicolumn{9}{|c|}{ Resistance to bending } \\
\hline \multirow[t]{3}{*}{ Support } & 1543.9 & 1285.1 & Z107 & 12.1 & 160 & 201 & $>2000$ & $>2000$ \\
\hline & & & $\mathrm{Z} 137$ & 16.4 & 110 & 148 & 1735.9 & $>2000$ \\
\hline & & & P6 & 5.8 & 97 & 155 & $>2000$ & $>2000$ \\
\hline \multirow[t]{3}{*}{ Span } & 1375.4 & 1065.2 & $\mathrm{Z} 107$ & 12.2 & 160 & 201 & $>2000$ & $>2000$ \\
\hline & & & $\mathrm{Z} 137$ & 16.1 & 110 & 148 & $>2000$ & $>2000$ \\
\hline & & & P6 & 3.8 & 97 & 155 & $>2000$ & $>2000$ \\
\hline \multicolumn{9}{|l|}{ Resistance to shear } \\
\hline \multirow[t]{3}{*}{ Support } & 570.6 & 445.4 & Z107 & 9.6 & 160 & 201 & $>2000$ & $>2000$ \\
\hline & & & $\mathrm{Z} 137$ & 9.2 & 110 & 148 & 1497.0 & $>2000$ \\
\hline & & & P6 & 2.6 & 97 & 155 & $>2000$ & $>2000$ \\
\hline \multicolumn{9}{|c|}{ Resistance with regard to the resultant horizontal abutment reactions } \\
\hline \multirow[t]{3}{*}{ Total Abutments } & 696.0 & - & $\mathrm{Z} 107$ & 131.3 & 160 & 201 & 850 & 1070 \\
\hline & & & $\mathrm{Z} 137$ & 148.3 & 110 & 148 & 520 & 690 \\
\hline & & & P6 & 74.6 & 97 & 155 & 900 & 1450 \\
\hline
\end{tabular}

Table 5 Summary of numerical calculations results and design data for the viaduct B

\begin{tabular}{|c|c|c|c|c|c|c|c|c|}
\hline \multirow[t]{2}{*}{$\begin{array}{l}\text { Location of } \\
\text { section }\end{array}$} & \multirow[t]{2}{*}{$\begin{array}{l}\text { Design load } \\
\text { capacity } \\
{[\mathrm{kNm}] /[\mathrm{kN}]}\end{array}$} & \multirow[t]{2}{*}{$\begin{array}{l}\text { Combined effects of } \\
\text { static loads by unique } \\
\text { combination }[\mathrm{kNm}] /[\mathrm{kN}]\end{array}$} & \multirow[t]{2}{*}{$\begin{array}{l}\text { Recorded } \\
\text { signal }\end{array}$} & \multirow{2}{*}{$\begin{array}{l}\text { Effects of } \\
\text { mining } \\
\text { tremors } \\
{[\mathrm{kNm}] /[\mathrm{kN}]}\end{array}$} & \multicolumn{2}{|c|}{$\begin{array}{l}\text { Extreme horizontal } \\
\text { acceleration from } \\
\text { tremors }\left[\mathrm{mm} / \mathrm{s}^{2}\right]\end{array}$} & \multicolumn{2}{|c|}{$\begin{array}{l}\text { Resistance expressed by } \\
\text { extreme horizontal } \\
\text { acceleration }\left[\mathrm{mm} / \mathrm{s}^{2}\right]\end{array}$} \\
\hline & & & & & $\begin{array}{l}\text { After } \\
\text { filtration }\end{array}$ & $\begin{array}{l}\text { Without } \\
\text { filtration }\end{array}$ & $\begin{array}{l}\text { After } \\
\text { filtration }\end{array}$ & Withoutfiltration \\
\hline \multicolumn{9}{|c|}{ Resistance to bending } \\
\hline \multirow[t]{3}{*}{ Span } & \multirow[t]{3}{*}{$12,985.3$} & \multirow[t]{3}{*}{8182.9} & Z107 & 49.4 & 160 & 201 & $>2000$ & $>2000$ \\
\hline & & & Z137 & 54.63 & 110 & 148 & $>2000$ & $>2000$ \\
\hline & & & P6 & 30.62 & 97 & 155 & $>2000$ & $>2000$ \\
\hline \multicolumn{9}{|c|}{ Resistance to shear } \\
\hline \multirow[t]{3}{*}{ Support } & \multirow[t]{3}{*}{1629.2} & \multirow[t]{3}{*}{1097.4} & Z107 & 4.80 & 160 & 201 & $>2000$ & $>2000$ \\
\hline & & & Z137 & 4.33 & 110 & 148 & $>2000$ & $>2000$ \\
\hline & & & P6 & 2.45 & 97 & 155 & $>2000$ & $>2000$ \\
\hline \multicolumn{9}{|c|}{ Resistance with regard to the resultant horizontal abutment reactions } \\
\hline \multirow{3}{*}{$\begin{array}{l}\text { Total by } \\
\text { parallel axis }\end{array}$} & \multirow[t]{3}{*}{208.1} & \multirow[t]{3}{*}{-} & Z107 & 27.02 & 160 & 201 & 1232.5 & 1548.3 \\
\hline & & & Z137 & 33.52 & 110 & 148 & 683.0 & 919.0 \\
\hline & & & P6 & 26.72 & 97 & 155 & 755.5 & 1207.3 \\
\hline \multirow{3}{*}{$\begin{array}{l}\text { Total by } \\
\text { perpendicular } \\
\text { axis }\end{array}$} & \multirow[t]{3}{*}{150.0} & \multirow[t]{3}{*}{-} & Z107 & 9.68 & 160 & 201 & $>2000$ & $>2000$ \\
\hline & & & Z137 & 24.84 & 110 & 148 & 664.3 & 893.7 \\
\hline & & & P6 & 8.32 & 97 & 155 & 1748.8 & $>2000$ \\
\hline
\end{tabular}


the construction design. They were calculated with the following assumptions:

- no use of the plastic reserve of the cross-section,

- load applied on the upper beam flange,

- plate girder protected against buckling,

- St3 steel with computational strength $f_{\mathrm{d}}=190 \mathrm{MPa}$.

Based on the analysis of the results of numerical calculations, it can be assumed that the resistance of the viaduct expressed by extreme values of horizontal and accidental accelerations of the Earth's surface is:

- maximum acceleration value after band filtration $0-10 \mathrm{~Hz}$ ok. $650 \mathrm{~mm} / \mathrm{s}^{2}$,

- peak value of actual acceleration about $900 \mathrm{~mm} / \mathrm{s}^{2}$.

As in the case of the viaduct $\mathrm{A}$, the horizontal resistance of the railway viaduct $\mathrm{B}$ calculated numerically using the time analysis method (THA) is determined by the horizontal force, but induced in a direction perpendicular to the track axis. The resistances obtained with regard to bending and shearing of the main beam are not less than $2 \mathrm{~m} / \mathrm{s}^{2}$ of the horizontal acceleration of soil due to paraseismic tremor. Such resistance values are significantly higher than those forecasted for this area at $270 \mathrm{~mm} / \mathrm{s}^{2}$.

\subsection{Estimation of Dynamic Resistance of the Viaduct-C}

The dynamic resistance of flyover $\mathrm{C}$ was carried out analogously to those mentioned above. Based on the results of the numerical analysis of the viaduct subjected to paraseismic interactions, it can be stated that:

- there is no threat to the facility's safety related to exceeding the bending strength of the main beams and bearing capacity of the vertical load provided that mining tremors acting on the object will be characterized by vertical soil acceleration not greater than $2.6 \mathrm{~m} /$ $\mathrm{s}^{2}$,

- The critical limit state is the possibility of slip (travel) of the sliding (roller) bearings in the reverse direction, i.e., perpendicular to the main axis of the viaduct, resistance would be characterized by acceleration of soil in this direction equal to $1.4 \mathrm{~m} / \mathrm{s}^{2}$ and would signify he viaduct to be in good technical condition,

- considering the poor condition of the support bearings (which results in a higher coefficient of friction), the actual viaduct resistance can be estimated at no more than $0.9 \mathrm{~m} / \mathrm{s}^{2}$.

Bearing in mind the above statements, it should be assumed that the resistance of the viaduct in question expressed by extreme values of horizontal and accidental accelerations of the earth's surface is, after filtration, in the band of $0-10 \mathrm{~Hz}$ ok. $900 \mathrm{~mm} / \mathrm{s}^{2}$.

\subsection{Estimation of Dynamic Resistance of the Viaduct-D}

As a result of the load capacity analysis based on the numerical model of the viaduct $\mathrm{D}$, the limit state of load bearing capacity of fixed and unidirectional sliding bearings was selected due to the horizontal reaction components induced by them, caused by paraseismic loads. The supporting structure of the viaduct due to vertical variable load-movement is also subjected to horizontal forces from side impacts and associated with accelerating or braking trains. The first operate transversely to the viaduct axis, and the others along it. The side impact force is not normally located along the viaduct span. It indicates that possible impact can occur in each of the two support zones or in the span. Their full load-bearing capacity in this direction was used in the analysis. In the analysed viaduct there is a clear coupling of vertical and horizontal vibrations resulting in the appearance of horizontal components of support reactions caused by the vertical component of paraseismic kinematic excitation. This phenomenon is unusual in building constructions. In this case, it is caused by the asymmetry of the structure due to the location of the bearings on axes not perpendicular to the main axis of the span. This promotes its torsional vibrations around this axis. From the point of view of the viaduct's resistance to mining excitations, the situation is unfavorable. This is due to the fact that the vertical components and horizontal excitations jointly affect the critical elements of the supporting structure-in the case of the viaduct D-the structural bearings.

Based on the results of numerical calculations, considering a slight margin of error due to the inaccuracies of the analysis, it can be assumed that the resistance of the viaduct $\mathrm{D}$ expressed in extreme values of horizontal and accidental accelerations of the Earth's surface, after filtration, in the $0-10 \mathrm{~Hz}$ band is about $850 \mathrm{~mm} / \mathrm{s}^{2}$.

\section{Summary}

The above analyses of resistance of railway viaducts (B and $\mathrm{D}$ ), as well as road viaducts (A and C), were made using reliable calculation models of load-bearing structures of both types of existing objects. The load history method with kinematic excitations was used, which were real accelerograms recorded in the region close to the location of the objects. The final assessments were made with caution and, therefore, were done conservatively. Worthy of note is the fact that the final dynamic resistance of both 
existing bridges was determined by the combined horizontal force, which suggests paying close attention to the methods of foundation of viaducts on abutments and columns. The general technical condition of the object as well as the condition of the support and expansion joints are not without significance. Unfortunately, these elements negatively affect the value of dynamic resistance (by lowering it) and at the same time they are often difficult to take into account.

However, it should be borne in mind and the authors clearly emphasize that the analysis carried out in this respect is unusual, and what is more, there are no results available for measuring the viaduct response exposed to mining tremors. No such measurements were carried out in any region of our country. Therefore, there is no relevant experimental base that could be used as a source of information on the behaviour of viaducts during mining tremors. Therefore, there is also no useful numerical data for comparing and possibly validating numerical models used in the analysis of various bridge structures threatened by the impact of mining tremors. So far, the authors have not received any information about possible damage to existing bridge structures resulting from paraseismic interactions. Most likely the resistance of existing bridge structures is higher than that resulting from the conducted analyses. This finding requires broader field tests in the future.

Open Access This article is licensed under a Creative Commons Attribution 4.0 International License, which permits use, sharing, adaptation, distribution and reproduction in any medium or format, as long as you give appropriate credit to the original author(s) and the source, provide a link to the Creative Commons licence, and indicate if changes were made. The images or other third party material in this article are included in the article's Creative Commons licence, unless indicated otherwise in a credit line to the material. If material is not included in the article's Creative Commons licence and your intended use is not permitted by statutory regulation or exceeds the permitted use, you will need to obtain permission directly from the copyright holder. To view a copy of this licence, visit http://creativecommons. org/licenses/by/4.0/.

\section{References}

1. Ebrahimi Motlagh HR, Rahai A (2017) Dynamic response of a continuous-deck bridge with different skew degrees to near-field ground motions. Int J Civ Eng 15:715-725. https://doi.org/10. 1007/s40999-017-0169-8

2. Dorota Olszewska, Grzegorz Mutke: A study of site effect using surface-downhole seismic data in a mining area. In: 16th european conference on earthquake engineering, 18-21 June 2018, Thessaloniki, Greece. https://tcs.ah-epos.eu/eprints/2123/

3. Pradelok S (2012) The influence of higher modes vibrations on local cracks in node of lattice girders bridges. Archives of Civil Engineering 58(2):209-221. https://doi.org/10.2478/v.10169012-0013-0
4. Pradelok S (2016) Theoretical analysis of the possibilities to improve the dynamic parameters of the road arch bridge. Proc Eng 161:1090-1095. https://doi.org/10.1016/j.proeng.2016.08. 853

5. D. Mrozek, M. Mrozek, J. Fedorowicz (2017) The protection of masonry buildings in a mining area. Procedia Engineering pp 184-191, https://doi.org/10.1016/j.proeng.2017.06.202

6. Mrozek D, Mrozek M, Fedorowicz J (2017) Analysis of an effectiveness of expansion joints in the multi-family building loaded by mining activities. Czas Inż Lą Środ Archit 2017 t. 34 z. 64, nr 2/II, s. 199-210. http://dx.doi.org/10.7862/rb.2017.92

7. Wei B, Li C, He X (2019) The applicability of different earthquake intensity measures to the seismic vulnerability of a highspeed railway continuous bridge. Int J Civ Eng 17:981-997. https://doi.org/10.1007/s40999-018-0347-3

8. Shahrouzi M, Nouri G, Salehi N (2017) Optimal seismic control of steel bridges by single and multiple tuned mass dampers using charged system search. Int J Civ Eng 15:309-318. https://doi.org/ 10.1007/s40999-016-0102-6

9. Grzegorz Poprawa, Stefan Pradelok, Marek Salamak, P. Łaziński. Operational modal analysis in model updating of a truss railway bridge. In: Proceedings of 7th IOMAC, Ingolstadt, 2017: 64-67. https://www.researchgate.net/publication/320287297_Opera tional_Modal_Analysis_in_Model_Updating_of_a_Truss_Rail way_Bridge

10. Grzegorz Poprawa, Marek Salamak, Stefan Pradelok. Specific dynamic response of truss railway bridge identified using operational modal analysis as an extension of typical dynamic load testing. Proceedings of ISMA 2018: 1597-1606. https://past. isma-isaac.be/isma2018/proceedings/program/

11. Grzegorz Poprawa, Marek Salamak, Stefan Pradelok. Operational modal analysis in commissioning dynamic tests of different types of footbridges - experiences and conclusions. Proceedings of 8th IOMAC, 2019. https://www.scopus.com/record/display.uri?eid= 2 -s2.0-85069498376\&origin=inward\&txGid= c62b01f451119656dd4055a923708831

12. Ansari M, Daneshjoo F, Mohammadi MS (2017) On estimation of seismic residual displacements in reinforced concrete singlecolumn bridges through force-displacement method. Int J Civ Eng 15:473-486. https://doi.org/10.1007/s40999-016-0079-1

13. Daniel L, Kortiš J (2017) The comparison of different approaches to model vehicle-bridge interaction. Proc Eng 190:504-509. https://doi.org/10.1016/j.proeng.2017.05.370

14. Yazdania M, Jahangirib V, Marefatc MS (2019) Seismic performance assessment of plain concrete arch bridges under nearfield earthquakes using incremental dynamic analysis. Eng Failure Anal 106, https://doi.org/10.1016/j.engfailanal.2019.104170

15. Khan AKMTA, Bhuiyan MAR, Ali SB (2019) Seismic responses of a bridge pier isolated by high damping rubber bearing: effect of rheology modeling. Int J Civ Eng 17:1767-1783. https://doi. org/10.1007/s40999-019-00454-x

16. Lipski Z, Mrozek D (2012) Numerical model of extreme kinematic excitations using principal component analysis. In: 10th International conference on new trends in statics and dynamics of buildings, Bratislava, October 3-5, on CD, 132-135 oai:repolis.bg.polsl.pl:26463

17. Hilber Hans M, Hughes TJR, Robert TL (1977) Improved numerical dissipation for time integration algorithms in structural dynamics. Earthq Eng Struct Dyn. https://doi.org/10.1002/eqe. 4290050306

18. Newmark NM (1959) A method of computation for structural dynamics. J Eng Mech Div 85(3):67-94 